\title{
Enhancing female adolescents' engagement in Physical Education classes through video-based peer feedback
}

\author{
Omar Trabelsi ${ }^{1, *}$, Adnene Gharbi ${ }^{1}$, Liwa Masmoudi', and Maher Mrayeh² \\ ${ }^{1}$ High Institute of Sports and Physical Education, University of Sfax, Sfax, Tunisia; and ${ }^{2}$ High Institute of Sports and Physi- \\ cal Education of Ksar Said, University of Manouba, Manouba, Tunisia
}

Copyright: (C) 2020 O. Trabelsi et al. This is an open access article licensed under the Creative Commons Attribution License (https://creativecommons.org/licenses/by/4.0/).

\begin{abstract}
Background: Although studies on adolescent girls' disengagement in Physical Education (PE) abound in the literature, most of all investigated root causes only, while few took the initiative to address the inherent issue. Objective: This study primarily aimed at investigating the impact of peer-to-peer feedback interactions on female adolescents' engagement in PE classes, in addition to assessing the potential of video technology in the enhancement of this experience. Methods: A total of 47 Tunisian female students, aged 17 to 18 years, took part in a six-week experiment, during which they went through different long jump learning conditions. A comparative methodology was implemented, involving two experimental conditions including a vision-based feedback group (VsFG; $n=15)$ and a video-based feedback group (VdFG; $n=12$ ), as well as a control group (CG; $n=20$ ). Data was collected using motor performance tests, a custom-designed theoretical knowledge test, feedback provision rates, motivation and feeling scales, questionnaires, and interviews. Results: Data analysis revealed that the video-based peer feedback approach was more efficient in terms of its ability in enhancing the studied population's engagement in the learning process during PE classes. Indeed, the positive effects of vision-based peer feedback interactions were observed only on female students' emotional engagement ( $\mathrm{CG}<\mathrm{VsFG}, p<.001)$, whereas the video-based peer feedback interactions were potent enough to enhance female students' motor (CG < VdFG, $p=.019)$, cognitive (CG < VdFG, $p=.002$ ), emotional (CG $<$ VdFG, $p<.001$ ) and socio-interactional (VsFG < VdFG, $p<.001$ ) engagement in PE classes. Conclusions: The findings of this study concluded that peer-to-peer feedback interactions during PE classes were inefficient without the mediation role of the video technology.
\end{abstract}

Keywords: teaching/learning strategies, pedagogical issues, cooperative/collaborative learning, improving classroom teaching

\section{Introduction}

Even though "gym culture" has been widely spreading in the feminine community during the past decades, founding and maintaining female adolescents' engagement in physical activity remains one of the most serious challenges for Physical Education (PE) teachers. Once PE becomes optional, as in many countries around the world, enrolment rates tend to decrease significantly, with a more noticeable decrease among adolescent girls than adolescent boys (Crosswhite, Wilde, \& Vescio, 2003; Mikaelsson, Rutberg, Lindqvist, \& Michaelson,

\footnotetext{
* Address for correspondence: Omar Trabelsi, High Institute of Sports and Physical Education, University of Sfax, Airport Road, Km 3,5, BP 384, 3000 Sfax, Tunisia. E-mail: trabelsi.omar@issepsf.u-sfax.tn
}

2020; Owen, Curry, Kerner, Newson, \& Fairclough, 2017; Pearson, Braithwaite, \& Biddle, 2015). This low participation rate and high drop out of adolescent girls in $\mathrm{PE}$ is not unique to one particular country; it is rather a worldwide issue (Crosswhite et al., 2003).

Every didactic situation proposed to a group of learners is unavoidably unsuitable for part of them. Some might find it too easy to constitute a challenge or to provoke new learning, while some others might experience difficulties with understanding the task and, thereby, with getting involved in it (Perrenoud, 2012). Thus, Amade-Escot (2016) argues that the management of mixed groups by PE teachers frequently requires separating the learners and proposing different situations to each gender or defining specific rules that comply with the different characteristics of the two sexes. Indeed, if we manage to understand 
why many girls are leaving high school with negative feelings about PE, we might be able to implement effective strategies to deal with the trend accordingly. Thereupon, the current study suggested giving female adolescents the opportunity to engage more actively in the learning process during PE classes by fostering peer-to-peer interactions - often observed as feedback on each other performances - using some technological means, as introduced later along with this study.

The teaching/learning relationship has been generally considered as a dynamic process, rather than a one-way knowledge transmission process (Askew \& Carnell, 1998). This dynamicity is supported by a whole range of other processes, among which we can state feedback (Askew, 2004). Gielen, Peeters, Dochy, Onghena, and Struyven (2010) suggest that learning is a process of continuously modifying knowledge and skills and that feedback is essential to guide, test, and redirect the learner's thinking. Briefly, the feedback process represents that information which is meant to enlighten the difference between the state of the objective and the performance of the learner during a learning situation (Merian \& Baumberger, 2007).

One of the toughest challenges that a teacher can encounter in PE is to find sufficient time to provide feedback and reinforcement for his students during learning situations. For this reason, peer-assisted learning strategies could interfere as effective ways to help students receive feedback, instructions, and reinforcement from their classmates more frequently than a teacher could provide (S. E. Carr et al., 2016). Peer feedback is provided by equal status learners and can be regarded as a form of formative assessment - the counterpart of teacher feedback (Huisman, Saab, van den Broek, \& van Driel, 2019), and also as a form of collaborative learning (Van Gennip, Segers, \& Tillema, 2010). In both cases, the learner expects an intermediate check of his performance against the criteria, accompanied by feedback on his strengths, weaknesses and/or tips for improvement (Aljadeff-Abergel, Peterson, Wiskirchen, Hagen, \& Cole, 2017). A number of recent studies have pointed to the importance of this type of interaction between students in the teaching/ learning process in PE. For example, Lafont (2012) suggested that, during PE classes, students' cognitive and social skills improved as a result of receiving feedback from members of their team. As well, and as a consequence of communicational and cognitive development, motor performance and tactical choices were reported to have improved. Moreover, the findings of Goodyear, Casey, and Kirk (2014) showed that female students who had previously disengaged from PE demonstrated higher levels of motivation after being afforded the opportunity to get involved in a peer-to-peer interaction process, through which they can exchange analyses, evaluations, feedback on each other's performance. However, peer feedback is not always as effective as teacher's feedback (Gielen, Tops, Dochy, Onghena, \& Smeets, 2010), owing to the fact that compared to teachers, peers are not field experts (Hanrahan \& Isaacs, 2001). Peer feedback may be partially correct, fully incorrect or misleading since the peer assessor is usually not regarded as a "knowledge authority". This could lead to more restraints in accepting a peer's judgment or advice (Hanrahan \& Isaacs, 2001). Furthermore, when asked to provide feedback, peers are likely to experience some difficulties with the time lag between the performance and the moment of feedback provision, where the student fails to evoke the action about which is the peer comments (Hortigüela Alcalá, Palacios Picos, \& López Pastor, 2019; Kim \& Arbel, 2019). In addition, in a PE class, the observer - a female student in our case - might feel unable to construct feedback utterances after a one-time demonstration of a motor skill, essentially when the executed movement is very quick (Potdevin et al., 2018). Therefore, new pedagogical techniques were required to tackle these problems and help female students engage more effectively in the peer feedback process during PE classes. For the abovementioned reasons, the researchers have chosen to resort to video technology or what is called, in the exact terms in the teaching/learning research literature, "video-based feedback".

Verbal feedback based on visual memory neural representations is the most common mode of feedback in PE (Hermassi, Sellami, Bouhafs, Schwesig, \& De Giorgio, 2019). Once a teacher or a student is asked to provide feedback in PE classes, full concentration on the motor performance, on which feedback will be later given, is required in order to detect weaknesses, as well as strengths (Ward \& Lee, 2005). Nevertheless, this mode of feedback in PE has its limitations, including problems of detecting all controversial points from a one-time demonstration (Palao, Hastie, Cruz, \& Ortega, 2015), recalling all observations and notes when it is time to produce feedback (Maxwell, Masters, \& Eves, 2003), and most importantly the quality and accuracy of the provided feedback (Carless, 2013; Gielen, Peeters, et al., 2010; Hanrahan \& Isaacs, 2001). According to Luck and Vogel (1997), visual short-term memory is very limited by the number of actions rather than the number of features that must be remembered. Thus, when someone tries to focus on a series of actions or activities happening in a brief time, he later might fail to recall all the observed scenes. Therefore, using video recording equipment could help tackle all these problems. When invested in feedback activities, 
video technology has the potential to enhance learning through the incorporation of a rich visual format with many features such as replaying any desired moments of the performance, zooming on unclear points and replaying brief movements in slow motion (BenitezSantiago \& Miltenberger, 2016; Hung, 2016; Kretschmann, 2017). Furthermore, video sequences can be stored and replayed at student's convenience (Crook et al., 2012).

In short, the current research project aimed at enhancing adolescent girls' engagement in PE classes through fostering peer-to-peer feedback exchange activities during learning situations. In parallel, the study investigated the probable effects of video technology on the flow of this kind of activity.

\section{Methods}

\section{Participants}

Initially, 62 adolescent girls, aged 17 to 18 , agreed to participate in the study. However, as a result of missed classes and/or not completing post-tests, only 47 female students (body height $1.62 \pm 0.04 \mathrm{~m}$, body weight $56.7 \pm 4.5 \mathrm{~kg}$ ) were included in the final analysis. All of them were registered in the third grade of the Tunisian secondary educational system at the Monji Slim high school in the city of Sfax. The school selection depended on its good PE infrastructure and the availability of the necessary pedagogical equipment for the practical intervention. Participants were split into three groups: two experimental groups, vision-based feedback group (VsFG; $n=15$ ) and video-based feedback group (VdFG; $n=12$ ); and one control group $(\mathrm{CG} ; n=20)$.

Each group included female students from the same class. The selection of the classes relied on the cyclic planning of the physical activities practiced at the school, as we had to pick out three classes about to initiate long jump learning (the suggested activity in this study). Homogeneous sampling was not possible within this study, as the researchers aimed to compare the usefulness of vision-based peer feedback and video-based peer feedback amidst an authentic educational situation.

Approval for accessing the aforementioned public institution, with videotaping equipment, was sought and gained from all relevant stakeholders, including the Regional Commissary for Education of Sfax II, the scientific committee in the High Institute of Sports and Physical Education of Sfax, the school administration, PE teachers involved in the project and parents of the students who participated in this study.

\section{Procedures}

A 6-week experiment was carried out (4 weeks of learning sessions and 2 weeks of pre- and post-testing). All three groups participated in a regular long jump learning cycle consisting of four lessons, which lasted for 120 min each. All lessons had the same structure; warm-up, initial information (objective statement), main part, and lesson summary. Learning sessions took place once a week. The main part of each lesson involved two learning situations followed by an evaluative situation at the end. Each group received a specific pedagogical treatment during the main part of each session.

\section{$C G$}

This group was used as a benchmark to measure the improvement rates, if they exist, of both experimental groups. The participants belonging to this group received no feedback and no regulatory interventions from their teacher concerning their performances during the main part of each lesson. The researchers also made sure to prevent, in a polite manner, any kind of interaction between the students.

\section{$V_{S} F G$}

Students in this group were asked to choose their partners, with whom feedback will be exchanged, on condition that the participants had to swap partners in every learning session. Peer-to-peer feedback exchange activities took place at the end of every learning situation, where peers had to concentrate on each other performances so that they produce feedback based on detected images, stored inside their visual memories. The VsFG consisted of 20 female students during the practical intervention. After checking attendance at all learning sessions and post-tests, the results of 5 students were discarded.

\section{$V d F G$}

The same procedures used in the VsFG were implemented with participants of this group, except that this time the feedback provision was mediated through videotaped sequences of students' motor performances. In other words, videotaping equipment was provided to record students' performances. Instant recordings in slow motion were offered to partners in order to provide each other with feedback, based on what they have just seen on the video. Replay, pause, and zoom options were available at the students' convenience. For video recording, 2 iPhone devices (Apple, Cupertino, CA, USA) were placed within 2 meters of the sandpit.

It should be noted that learning sessions were scheduled to take place once a week for each group, on three separate days from 8 to 10 am (CG on Monday, 
VsFG on Wednesday, and VdFG on Friday) in order to prevent all sorts of inter-group influence.

\section{Data collection}

\section{Motor performance}

In order to study the motor performance in long jump, quantitative data was collected after conducting motor tests before and immediately after the experimental period (pre and post-test). The distance crossed jumped by each participant after jumping from the take-off point to the sandpit was gauged by means of a decameter. We made sure that the test conditions were similar during both test times for all the participating students. Each student had the right to take three attempts and the best of three crossed distances was recorded.

\section{Theoretical knowledge}

Knowledge about long jump rules and technical aspects was measured, before and immediately after the experimental period (pre and post-test) by means of a custom-designed written test. The test items were conceived following discussions with a number of teachers, specialized in long jump, who confirmed that the investigation tool content adequately complies with the Tunisian PE official curriculum. The initial version of the investigation tool was first developed using content from manuals related to track and field (G. Carr, 1999; Guthrie, 2003). The final version of the test consisted of 8 multi-choice questions; 3 of them targeted the regulatory aspects and 5 others the technical aspects. One mark was allocated to each correct answer and a total of 14 marks was required to get full marks in the test. In one question, one or more answers could be keyed as correct. Questions 1 and 4 contained a single correct answer; questions 2, 3, 5 and 8 contained 2 correct answers. This explains how 14 marks could be collected from 8 questions. The test was designed in French and subtitled in Arabic (students' native language) in order to minimize misunderstandings caused by language issues that might negatively influence the efficiency and the validity of the investigation tool.

\section{Feedback provision rate}

In order to compare the $\mathrm{VsFG}$ and $\mathrm{VdFG}$ feedback provision rates, verbal feedback utterances of each student from both groups, in all 4 learning sessions, were recorded. After digital audio data transcription, the amounts of produced feedback in each learning session were summed. The mean feedback provision rate from all sessions was calculated for each subject.

\section{Motivation}

The Situational Motivation Scale (SIMS), developed by Guay, Vallerand, and Blanchard (2000), was implemented to measure the intrinsic motivation rates of students from all groups. The three items of the instrument had to be rated on a 7 -grade scale $(1=$ strongly disagree, $4=$ neutral stance, and $7=$ strongly agree).

\section{Affective status}

While participating in a specific activity, individuals might experience some changes in mood. Some may find it pleasurable, whereas others may find it unpleasant. Therefore, a feeling scale, developed by Hardy and Rejeski (1989), was used to measure the exercise affective component of the participants from all groups. The investigation tool is basically an eleven-point scale, that ranges from +5 to $-5(+5=$ very good,$+1=$ fairly good, $0=$ neutral stance, $-1=$ fairly bad, and $-5=$ very bad).

\section{Students' perception of the innovation}

To be able to examine the possible effects of video technology use in the PE teaching/learning process, the researchers took into account only the group in which students had lived the video-based feedback experience (VdFG). Both qualitative and quantitative data were collected using a questionnaire and retrospective interviews.

First, an eight-item questionnaire was introduced to VdFG participants. The Video-mediated Oral Feedback questionnaire (VOFQ) was first developed by (Hung, 2016), in order to investigate the effects of video technology on the online feedback sharing process in language learning. The VOFQ was amended in order to make it fit with the PE subject. The main objective of the questionnaire was to compare the video-based feedback to the conventional feedback modes from the participants' point of view. After editing and revising, the researchers checked the internal consistency of the questionnaire based on Cronbach's alpha coefficient. This step confirmed the reliability of the instrument as Cronbach's alpha coefficient exceeded .7.

For the same purpose, and to guarantee more credibility of the study's findings, semi-structured interviews were conducted in the participating students' native language, Arabic (Tunisian dialect). Twelve participants, randomly chosen, from $\mathrm{VsFG}$ and VdFG (6 girls from each group) took part in 15-minute interviews. Open questions were focused on the impact of the proposed feedback approach on female students' engagement in the learning process, the participants' perceptions regarding PE classes after the experimental intervention as well as the features and limitations of the proposed pedagogical approach. Participants' personal data and privacy protection were enshrined in the current study. All names mentioned in the interviews' excerpts are fictitious. 


\section{Statistical analysis}

All statistical tests were processed using STATISTICA software (Version 13.3.0; TIBCO Software, Palo Alto, CA, USA). All values were expressed as mean $\pm S D$ in text, and as mean $\pm S E$ in figures. Normality was confirmed using the Shapiro-Wilk test. A two-way mixed analysis of variance (ANOVA; 3 groups [CG, VsFG, $\mathrm{VdFG}] \times 2$ test times [pre- and post-test]) with repeated measures for the second factor was used to analyze data collected from motor performance and theoretical knowledge tests. Later, and to provide clearer information concerning the degree of benefit generated by each of the suggested treatments (teaching/learning strategies), percentages of delta values $(\Delta \%)$ were compared. The delta value $\Delta$ (absolute change) refers to the simple difference in the indicator over two periods in time ( $\Delta=$ post - pre) and $\Delta \%$ (relative change) expresses the absolute change as a percentage of the value of the indicator in the earlier period: $\Delta \%=(\Delta /$ post $) * 100)$. When about the motivation and feeling scales' results, the one-way ANOVA test was implemented for analysis. The independent samples $t$-test was used to analyze the results of the socio-interactional test. Post-hoc comparison was performed using the Bonferroni post-hoc test. Statistical significance was set at $\alpha=.05$. Effect sizes were calculated as eta-squared $\eta_{p}^{2}$ for ANOVA $\left(\eta_{\mathrm{p}}^{2} \geq .01\right.$, small effect size; $\eta_{\mathrm{p}}^{2} \geq .06$, medium effect size; $\eta_{\mathrm{p}}^{2} \geq .14$, large effect size), and as Cohen's $d$ for $t$-test ( $d \geq 0.2$, small effect size; $d \geq 0.5$, medium effect size; $d \geq 0.8$, large effect size).

\section{Results}

\section{Motor performance in long jump}

The statistical analysis demonstrated no significant effect of Group $\left(F(2,44)=1.09, p=.344, \eta_{\mathrm{p}}^{2}=.047\right)$. On the other hand, there was a significant effect of Learning $\left(F(1,44)=9.19, p=.004, \quad \eta_{\mathrm{p}}^{2}=.17\right)$, as well as significant interaction Group $\times$ Learning $\left(F(2,44)=4.34, p=.019, \eta_{\mathrm{p}}^{2}=.16\right)$.

Post-hoc results showed a significant improvement of the motor performance among VdFG participants, where VdFG post-test results $(2.19 \pm 0.40 \mathrm{~m})$ were significantly different $(p=.048)$ in comparison with pre-test results $(2.44 \pm 0.49 \mathrm{~m}$; Figure 1$)$.

By comparing the motor learning outcomes of all three groups ( 3 Groups $\times 2$ Test times), the statistical results indicated a significant difference $(p=.019)$ between $\Delta \%$ of VdFG and $\Delta \%$ of CG $(\Delta=0.24$, $\Delta=-0.20$, respectively), while no significant difference was observed between $\Delta \%$ of $\mathrm{VdFG}$ and $\Delta \%$ of VsFG $(\Delta=0.24, \Delta=0.10$, respectively $)$, nor between
$\Delta \%$ of $\mathrm{CG}$ and $\Delta \%$ of $\mathrm{VsFG}(\Delta=-0.20, \Delta=0.10$, respectively; Figure 2).

\section{Knowledge in long jump}

Concerning the theoretical knowledge in long jump, the statistical analysis of cognitive written tests results demonstrated significant effect of Group $(F(2,44)=4.53$, $\left.p=.016, \eta_{\mathrm{p}}^{2}=.17\right)$, together with significant effect of Learning $\left(F(1,44)=29.81, p<.001, \eta_{\mathrm{p}}^{2}=.040\right)$. Furthermore, significant interaction of Group $\times$ Learning $\left(F(2,44)=6.94, p=.002, \eta_{\mathrm{p}}^{2}=.24\right)$ was observed.

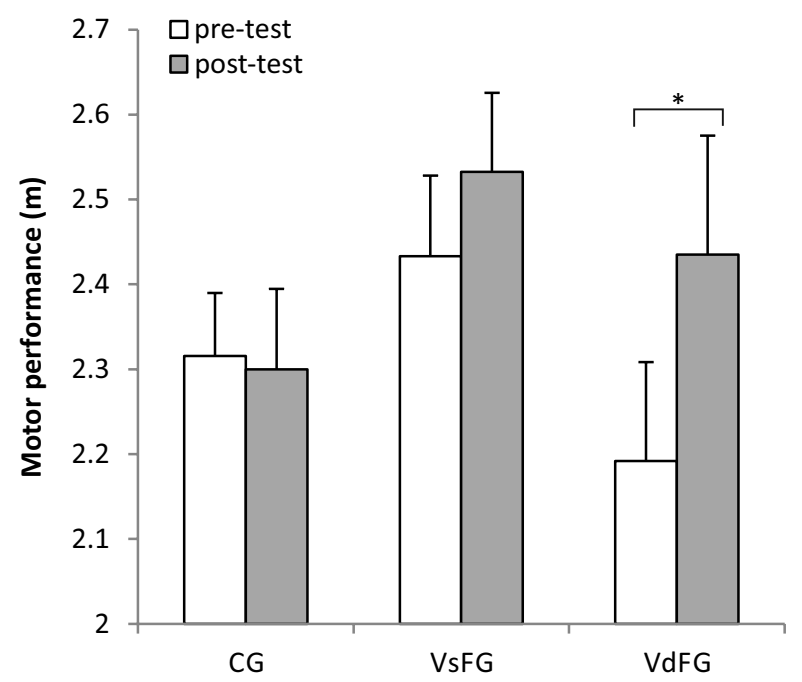

Figure 1. Means and SEs of motor performances of control group (CG), vision-based feedback group (VsFG) and video-based feedback group (VdFG) throughout test times (pre-tests and post-tests). $* p<.05$.

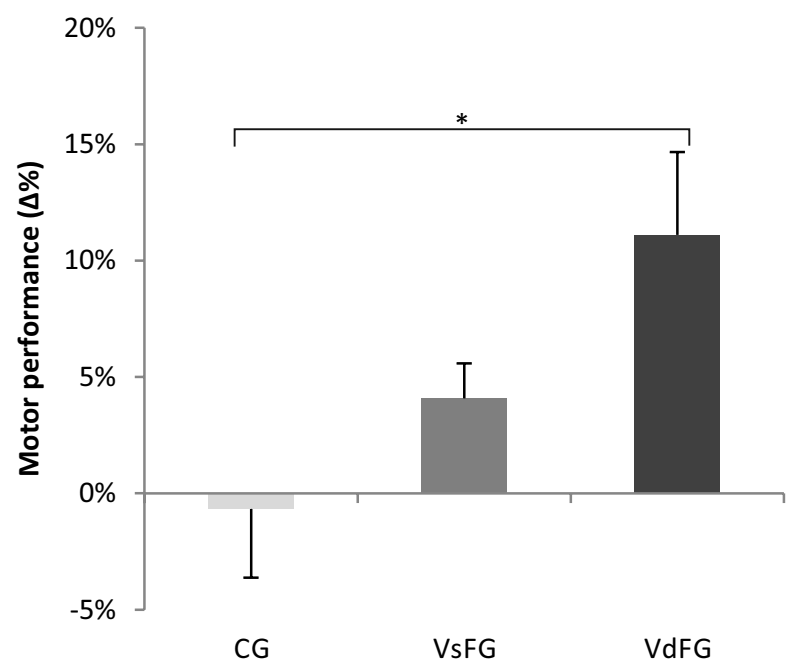

Figure 2. Perceived motor learning outcomes of control group (CG), vision-based feedback group (VsFG) and video-based feedback group (VdFG) expressed as change in per cents. ${ }^{*} p<.05$. 
Learning effects were spotted among VdFG students only, where a significant difference between VdFG pre-test $(5.33 \pm 1.78$ marks $)$ and post-test results $(8.5 \pm 1.98$ marks $)$ was statistically proved $(p<.001)$. Moreover, a significant difference $(p=.039)$ was observed when comparing VdFG and VsFG post-test results $(8.50 \pm 1.98,5.93 \pm 2.58$ marks, respectively). In addition, a significant difference $(p=.006)$ was observed when comparing VdFG post-test results $(8.50 \pm 1.98$ marks) with those of CG $(5.60 \pm 1.47$ marks; Figure 3).

By comparing the different cognitive learning outcomes of the three groups ( 3 Groups $\times 2$ Test times), the statistical analysis indicated a significant difference $(p=.002)$ between $\Delta \%$ of VdFG and $\Delta \%$ of CG $(\Delta=3.17, \Delta=0.40$, respectively), while no significant difference was observed between $\Delta \%$ of VdFG and $\Delta \%$ of VsFG $(\Delta=3.17, \Delta=1.40$, respectively $)$, nor between $\Delta \%$ of CG and $\Delta \%$ of VsFG $(\Delta=0.40$, $\Delta=1.40$, respectively; Figure 4).

\section{Socio-interactional effects}

Using the t-test, the researchers were able to compare feedback provision rates of $\mathrm{VsFG}$ and $\mathrm{VdFG}$ students. Indeed, the statistical analysis proved that $\mathrm{VdFG}$ 's results $(15.42 \pm 3.73)$ were significantly higher $(p<.001)$ when compared to those of VsFG (10.2 \pm 3.80 ; Figure 5). The effect size Cohen's $d$ was at 1.38 .

\section{Emotional effects}

Motivation

After analyzing the Situational Motivation Scale's results of all three groups statistically, the one-way ANOVA

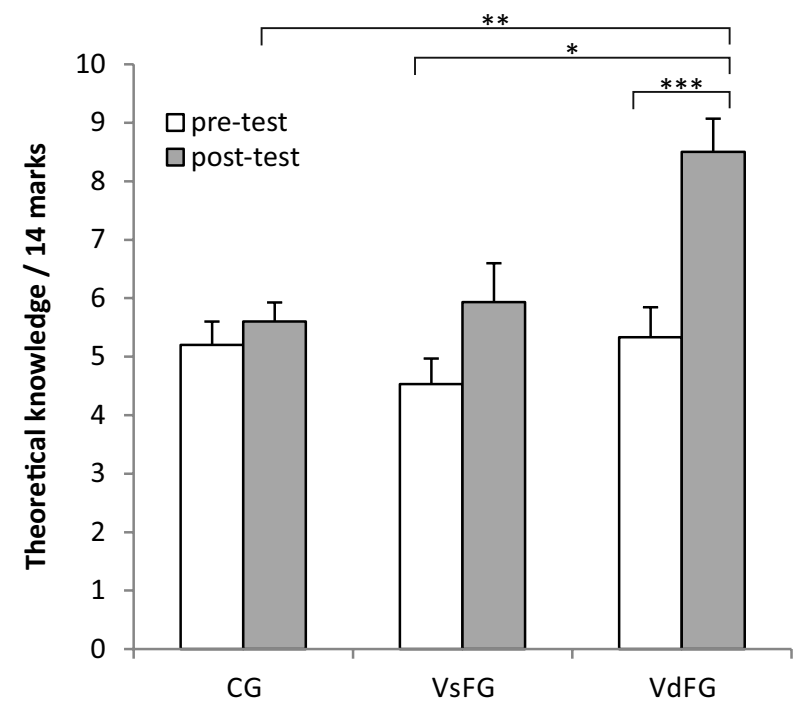

Figure 3. Means and SEs of cognitive written pre-test and post-test's results of control group (CG), visionbased feedback group (VsFG) and video-based feedback group (VdFG). ${ }^{*} p<.05,{ }^{* *} p<.01,{ }^{* * *} p<.001$. showed significant effect of Group $(F(2,44)=39.06$, $\left.p<.001, \eta_{\mathrm{p}}^{2}=.64\right)$. Indeed, the comparison of both VsFG and VdFG results $(15.93 \pm 3.06,17.75 \pm 2.42$, respectively) with those of $\mathrm{CG}(9.65 \pm 2.74)$ showed significant differences $(p<.001)$. Nevertheless, no significant difference was observed when comparing VsFG and VdFG results $(15.93 \pm 3.06,17.75 \pm 2.42$, respectively; Figure 6).

\section{Exercise effective component}

Concerning the Feeling Scale results of all the three groups, the ANOVA showed significant effect of

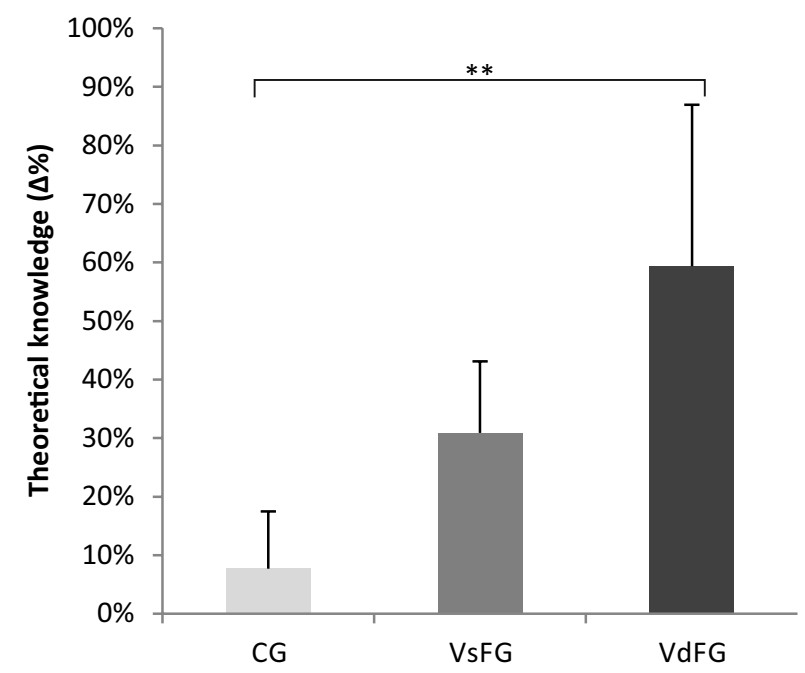

Figure 4. Perceived cognitive learning outcomes of control group (CG), vision-based feedback group (VsFG) and video-based feedback group (VdFG) expressed as change in per cents. ${ }^{* *} p<.01$.

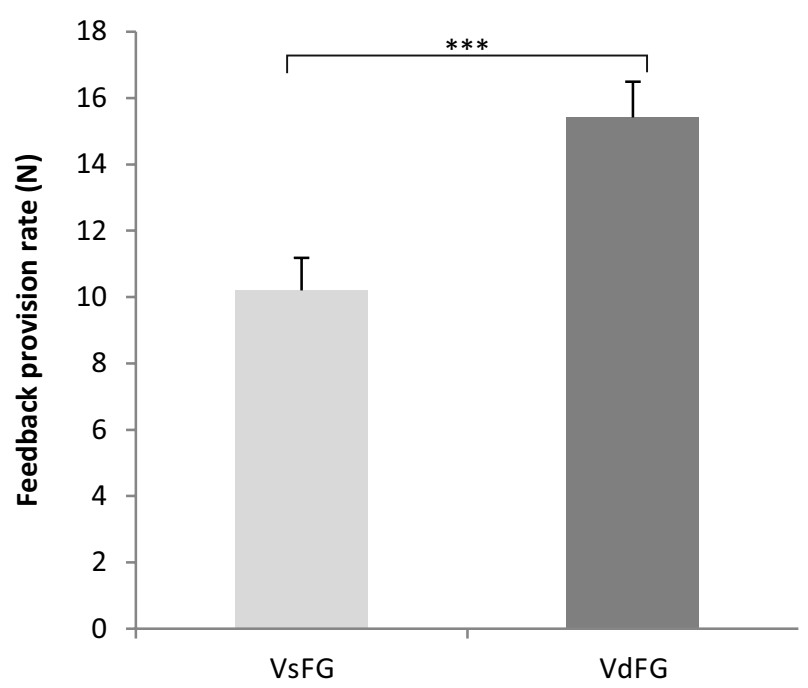

Figure 5. Means and $S E$ s of the feedback amount produced by vision-based feedback (VsFG) and videobased feedback (VdFG) groups during the 4-session long jump learning cycle. ${ }^{* *} p<.001$. 
Group $\left(F(2,44)=22.09, \quad p<.001, \quad \eta_{\mathrm{p}}^{2}=.50\right)$. In fact, the comparison of both VsFG and VdFG results $(2.60 \pm 1.35,3.50 \pm 1.62$, respectively) with those of CG $(-0.55 \pm 2.24)$ showed significant differences $(p<.001)$. However, no significant difference was observed when comparing VsFG and VdFG results $(2.60 \pm 1.35,3.50 \pm 1.62$, respectively; Figure 7).

\section{Female students' perception of innovation VOFQ}

Agreement and disagreement percentages about each item were calculated in order to explore the students' opinions regarding each required aspect. Means and

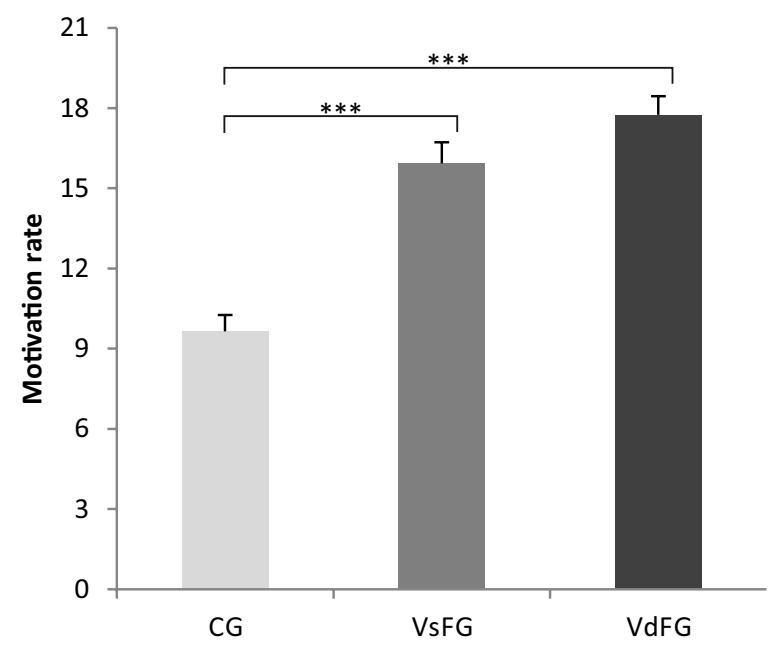

Figure 6. Means and SEs of motivation rates of control group (CG), vision-based feedback group ( $\mathrm{VsFG})$ and video-based feedback group (VdFG). ${ }^{* * *} p<.001$.

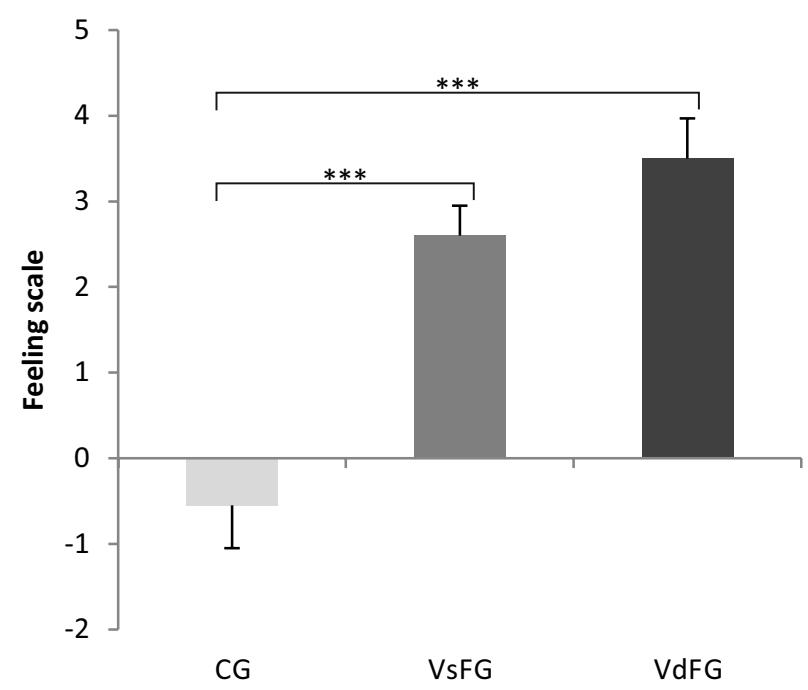

Figure 7. Means and SEs of the Feeling Scale results of control group (CG), vision-based feedback group (VsFG) and video-based feedback group (VdFG). $\quad * * * p<.001$. standard deviations were measured after assigning quantitative data to every level of agreement (Table 1).

In general, VdFG female students $(n=12)$ were quite positive about the video-based peer-to-peer feedback experiment. As shown in Table 1, when comparing video-based feedback and vision-based feedback, $83.35 \%$ of the VdFG participants agreed or strongly agreed that video technology can promote interactional behaviors among classmates and motivate them to produce more feedback (item $1+$ item 2 ).

Furthermore, $92 \%$ of the girls from the VdFG agreed or strongly agreed about the potential of videotaped sequences to allow the learner to observe and analyze his peer's performance in an easier and faster way (item 3). Also, $83.33 \%$ said that they paid more attention to the video content while providing or receiving feedback (item 4). Consequently, attentive observation of the video sequences enabled them to understand each other feedback in a better way and connect it to their performances when being feedback receivers (91.67\% agreed or strongly agreed; item 5), and also assisted them to improve the quality of their feedback, when being feedback producers ( $75 \%$ agreed or strongly agreed; item 6).

More importantly, $100 \%$ of the VdFG female students agreed and strongly agreed that videotaped sequences, compared to vision-based observations, provide the learner with the necessary support to recall and explain all recorded notes about his peer's performance in a better way (item 7). Finally, 91.7\% agreed or strongly agreed that video-based feedback coming from a peer is more credible, in terms of quality and efficiency than vision-based feedback (item 8).

\section{Interviews}

As a final step, and to make sure that our findings could be imputed to the video-based feedback project as well as to the peer-to-peer feedback exchange activities, qualitative data from semi-structured interviews with participants from both VdFG and VsFG were collected. Interviews' transcripts favored our hypothesis concerning the potential of technology-mediated collaborative learning in enhancing adolescent girls' engagement in PE classes. When being interviewed, girls from both groups showed positive attitudes and felt excited to express their thoughts about the 6-week experience.

Concerning peer-to-peer feedback exchange activities, "Yassmine" from VsFG said:

"I liked the idea. It was a new experience ... I learned how to accept criticism from others, whether it was from my teacher or classmates. That really helped me improve my capacities... I didn't use to like PE classes before and avoid attending them because I 
Table 1

Results of the Video-mediated Oral Feedback questionnaire used in the video-based feedback group

\begin{tabular}{|c|c|c|c|c|c|c|c|}
\hline \multirow[b]{2}{*}{ Item } & \multirow[b]{2}{*}{ Mean } & \multirow[b]{2}{*}{$S D$} & \multicolumn{5}{|c|}{ Rating } \\
\hline & & & 1 & 2 & 3 & 4 & 5 \\
\hline \multicolumn{8}{|l|}{$\begin{array}{l}\text { Compared to conventional feedback approaches, video-based } \\
\text { feedback can: }\end{array}$} \\
\hline 1) Promote interactions between me and my classmates. & 4.0 & 1.0 & $\begin{array}{c}0 \\
(0 \%)\end{array}$ & $\begin{array}{c}0 \\
(0 \%)\end{array}$ & $\begin{array}{c}2 \\
(16.7 \%)\end{array}$ & $\begin{array}{c}6 \\
(50 \%)\end{array}$ & $\begin{array}{c}4 \\
(33.3 \%)\end{array}$ \\
\hline 2) Motivate me to produce a greater amount of feedback. & 4.3 & 0.7 & $\begin{array}{c}0 \\
(0 \%)\end{array}$ & $\begin{array}{c}0 \\
(0 \%)\end{array}$ & $(8.3 \%)$ & $\begin{array}{c}4 \\
(33.3 \%)\end{array}$ & $\begin{array}{c}7 \\
(58.3 \%)\end{array}$ \\
\hline $\begin{array}{l}\text { 3) Help me with understanding and analyzing the content in } \\
\text { an easier and faster way. }\end{array}$ & 4.5 & 0.9 & $\begin{array}{c}0 \\
(0 \%)\end{array}$ & $\begin{array}{c}1 \\
(8.3 \%)\end{array}$ & $\begin{array}{c}0 \\
(0 \%)\end{array}$ & $\begin{array}{c}6 \\
(50 \%)\end{array}$ & $\begin{array}{c}5 \\
41.7 \%)\end{array}$ \\
\hline 4) Draw my attention much more. & 4.1 & 0.7 & $\begin{array}{c}0 \\
(0 \%)\end{array}$ & $\begin{array}{c}0 \\
(0 \%)\end{array}$ & $\begin{array}{c}2 \\
(16.7 \%)\end{array}$ & $\begin{array}{c}7 \\
(58.3 \%)\end{array}$ & $\begin{array}{c}3 \\
(25 \%)\end{array}$ \\
\hline $\begin{array}{l}\text { 5) Assist me in understanding my peer's feedback in a more } \\
\text { favorable manner. }\end{array}$ & 4.3 & 0.7 & $\begin{array}{c}0 \\
(0 \%)\end{array}$ & $\begin{array}{c}0 \\
(0 \%)\end{array}$ & $(8.3 \%)$ & $\begin{array}{c}6 \\
(50 \%)\end{array}$ & $\begin{array}{c}5 \\
(41.7 \%)\end{array}$ \\
\hline 6) Help me improve the quality of my produced feedback. & 4.2 & 0.8 & $\begin{array}{c}0 \\
(0 \%)\end{array}$ & $\begin{array}{c}0 \\
(0 \%)\end{array}$ & $\begin{array}{c}3 \\
(25 \%)\end{array}$ & $\begin{array}{c}4 \\
(33.3 \%)\end{array}$ & $\begin{array}{c}5 \\
(41.7 \%)\end{array}$ \\
\hline $\begin{array}{l}\text { 7) Help me remember all recorded notes about my peer's } \\
\text { performance in order to provide him with feedback. }\end{array}$ & 4.4 & 0.5 & $\begin{array}{c}0 \\
(0 \%)\end{array}$ & $\begin{array}{c}0 \\
(0 \%)\end{array}$ & $\begin{array}{c}0 \\
(0 \%)\end{array}$ & $\begin{array}{c}7 \\
(58.3 \%)\end{array}$ & $\begin{array}{c}5 \\
(41.7 \%)\end{array}$ \\
\hline 8) Make my peer's feedback more convincing and reliable. & 4.4 & 0.7 & $\begin{array}{c}0 \\
(0 \%)\end{array}$ & $\begin{array}{c}0 \\
(0 \%)\end{array}$ & $\begin{array}{c}1 \\
(8.3 \%)\end{array}$ & $\begin{array}{c}5 \\
(41.7 \%)\end{array}$ & $\begin{array}{c}6 \\
(50 \%)\end{array}$ \\
\hline
\end{tabular}

Note. $\quad$ Rating scale: 1 = strongly disagree, 2 = disagree, $3=$ neutral stance, $4=$ agree, $5=$ strongly agree.

hate PE as people always make fun of my feeble performances. But this experience made me believe that I can do better, I can learn and impress others."

On the same topic, "Eya" from VdFG stated:

"I love physical activity! It makes me look good and helps me stay in shape. But at school, things are completely different. Physical activities proposed in PE classes are not really my cup of tea. And even when I try to get involved, I find myself unable to make progress. In the end, I am not a professional athlete! But after this short experience, I think I did well. I learned how to improve my performance without my teacher's help and that really felt reinforcing ... Sharing feedback with your classmates and having the possibility to help others learn seemed to be a very interesting thing."

When asked about the limits of the peer-to-peer feedback exchange activities, "Salma" from the VsFG commented:

“... When observing my classmate's performance and giving feedback, I experienced some difficulties ... Long jump movements are really quick. When you try to concentrate on a specific part of the performance you might miss another. Observing with the naked eye is quite hard in such activities."

"Amal" from the same group also said:

“... At certain moments, I had doubts about my friends'feedback. They do not know too much about long jump and when they observe my performance they cannot detect all errors and controversial points. So how can I rely on information coming from them?"

When asked about introducing video technology in the peer-to-peer feedback process, "Fatma" from VdFG said:

“... It was like you were on social media websites. You post a video and people react to it and write comments, although this time the idea wasn't for fun but for an educational purpose ... It was an amazing experience! ... With video you can observe movements that you cannot properly see with the naked eye ... I think giving feedback on the basis of videotaped performances is by far easier and you can produce more feedback upon it as you would be sure of what you are saying after checking the video many times ... But I think more video cameras should be provided in order to avoid wasting time."

"Sirine" from the same group also said:

"... Thank you for the amazing experience. You created a learning environment full of motivation for us. I used to hate attending PE classes. I never managed to get good grades because of my weak physical capacities and my limited knowledge about physical activities ... But when you came up with this idea, I felt excited and motivated to learn and know more about sports ... The video technology provided us with many options such as replaying any part of the performance that we want to check again in slow 
motion ... Based on that, I modified many parts of my performance."

"Malak" from the same group as well explained: "At first impression, I felt afraid to be videotaped ... I did not think every girl would accept being video recorded by strangers in our conservative society ... But eventually, It was a great experience and I'm glad that I had the opportunity to take part in it."

\section{Discussion}

The aim of this study was to investigate the effects of promoting peer-to-peer feedback interactions during learning situations on adolescent girls' engagement in PE classes. Moreover, the researchers put forth efforts to deal with the aforementioned problems related to the peer-to-peer feedback process using video technology as a feedback vector. Thus, the survey centered on answering three essential questions; Can peer-topeer feedback interactions really help adolescent girls engage more effectively with the learning process during PE classes? If yes, can video technology increase the efficiency of this experience? And if no, can videobased peer-to-peer feedback appear as an alternative for the targeted aim?

In the light of the current study findings, it turned out that the potential of vision-based feedback interactions to enhance adolescent girls in the learning process, on both motor and cognitive sides, during PE classes are quite limited.

In fact, the findings of this study confirmed the absence of motor and cognitive improvements among girls who experienced vision-based feedback interactions along a 4-lesson long jump learning cycle. This has led the researchers to disagree with W. D. Carr, Volberding, and Vardiman (2011) who proposed peerassisted learning as an inclusive strategy for students with low abilities. These conflicting findings do not denote the inefficiency of the peer-assisted learning strategy but do provide strong evidence for the peerassisted learning inconsistency when shifting from one discipline to another (Dawson, van der Meer, Skalicky, \& Cowley, 2014).

Qualitative data collected from the conducted interviews vindicated the feeble effects of peer-to-peer feedback interactions on adolescent girls' motor and cognitive engagement in PE classes. Problems such as the indigence of vision-based observations (Salma interview) and the lack of belief in the reliability of peers' feedback (Amal interview), were enough to prevent girls from achieving progress towards the desired learning outcomes in the long jump activity.
On the other hand, the findings indicated a reasonable improvement of $\mathrm{VdFG}$ adolescent girls' motor performance and theoretical knowledge in long jump across test times. Indeed, video-based feedback interactions were able to help adolescent girls engage more actively with the learning process, on both motor and cognitive aspects. This is in complete agreement with the findings of Casey and Jones (2011) who reported that video technology has the potential to enhance learners' engagement in the motor and cognitive learning process during PE classes. Moreover, Potdevin et al. (2018) findings confirm that video technology can enhance less able students' engagement in the learning process by providing a rich and solid peer-to-peer feedback platform. Moreover, the current findings should help alleviate the misgivings of Palao et al. (2015) who concluded that video-based feedback interactions between students have no positive effects on their motor development during PE classes. Furthermore, Hung's (2016) findings highlighted the potential of video-based feedback interactions to allow learners to develop new learning strategies, with which students can reach the desired learning outcomes more adequately.

The data collected from the VOFQ and interviews provided further proofs of the strong potential of video technology in the enhancement of the peer-to-peer feedback exchange experience. Adolescent girls who lived that experience approved of the fact that video technology helped them to analyze their peers' performances in an easier and faster way, and also to understand the received feedback by connecting it to their videotaped performances. Furthermore, video-based feedback seemed to be more reasonable and trustworthy for them (VOFQ). Indeed, they found themselves able to modify their performances after watching video sequences of themselves performing and assimilating the received feedback (interviews).

Further, the findings of this study revealed another advantage of video technology related to its high potential to promote collaborative learning, not only through fostering social interactions in terms of quality (Hung, 2016; Hunukumbure, Smith, \& Das, 2017), but also in terms of quantity (Vaughn et al., 2016). On the basis of the socio-cultural theory of Lev Vygotsky (Daniels, 2016), in such socialized conditions, adolescent girls reciprocally benefited from each other feedback, which may consolidate the previously debated findings concerning the motor and cognitive learning outcomes of VdFG participants.

In line with these findings, Hung (2016) described the video-based feedback process, compared with conventional feedback approaches, as a platform of socialization, inside which peers tend to exchange more 
amount of feedback. Similarly, Crook et al. (2012) considered video-based feedback interactions as more advantageous with regard to students' engagement in the feedback provision process.

The significant difference between the feedback provision rates of $\mathrm{VsFG}$ and $\mathrm{VdFG}$ participants was also explained using the data collected from the VOFQ and the conducted interviews. Girls from VdFG agreed that the video-based feedback interactions motivated them to produce more feedback (VOFQ) even after learning sessions, where they felt confident with their comments and suggestions (interviews). In addition, girls valued the role of the video, as it helped them with remembering all the recorded notes about their peers' performances when it is time to provide feedback (VOFQ). It also allowed them to detect more controversial points they did not notice with the naked eye (interviews).

As far as the emotional outcomes are concerned, the findings of this study supported the potential of peer-to-peer feedback interactions, with and even without the mediation of video technology, to create a motivational climate among adolescent girls during PE classes. Similar impressions were concluded about the affective component of exercise, where girls from VsFG and VdFG felt good while practicing the long jump activity, with no significant differences observed between the results of both groups. In fact, both visionbased and video-based feedback exchange experiences were regarded as interesting and motivating.

In line with these findings, Hsia, Huang, and Hwang (2016) concluded that peer feedback not only contributes to students' learning but also enhances their learning motivation. Vazou, Ntoumanis, and Duda (2005) also emphasized that factors such as cooperation, autonomy, support, and evaluation of competence, in conditions where peers supported each other, were found to affect the general motivational climate in PE classes.

On the other hand, the findings of this study were in discordance with those of Potdevin et al. (2018) who reported that video-based feedback interactions, compared to conventional feedback approaches, have a greater positive impact on students' emotions in PE classes. In fact, the same emotional impact was observed among adolescent girls from both VsFG and VdFG in comparison with CG.

In the end, the present study did not take into consideration the technical execution in long jump. Motor performance investigations only focused on objective measurements. This is recognized as a limitation of the current study and should be considered for future research.

\section{Conclusions}

Data from this study suggest that adolescent girls' emotional engagement (i.e. motivation and affection) in PE classes can be increased through fostering peer-to-peer feedback interactions during learning situations. However, this kind of teaching/learning strategy was powerless in terms of motor, cognitive and social development when applied in PE classes. On the other hand, video technology strongly contributed to the enhancement of the functionality of the proposed feedback approach (i.e., peer-to-peer feedback), by increasing adolescent girls' engagement in PE classes, in all aspects. Even though both suggested peer feedback approaches had the same effects on emotional engagement, video-based feedback interactions were more effective, mainly in motor-behavioral, cognitive and socio-interactional engagement, than vision-based feedback interactions when exercised by adolescent girls during a long jump learning cycle in PE.

In brief, the video technology's favorable impact on the peer feedback process and its contribution to the enhancement of adolescent girls' engagement in PE classes allow for a positive conclusion for this work. However, it is quite important to bear in mind that this effort is not enough to drive adolescent girls' disengagement phenomenon beyond the PE field boundaries. Therefore, more attention should be paid to this critical issue in order to seek more effective treatment.

\section{Acknowledgments}

We would like to thank all students and PE teaching staff at the secondary school Monji Slim in Sfax, Tunisia who took part in the study. They were very welcoming and gave us the freedom that we needed to accomplish our research project. In addition, our sincere gratitude goes to all long jump specialists and teachers who contributed to designing the long jump knowledge written test. Also, we must thank the Regional Commissary for Education of Sfax II for cordially permitting the establishment of our survey inside the aforementioned educational institution.

\section{Conflict of interest}

There were no conflicts of interest. 


\section{References}

Aljadeff-Abergel, E., Peterson, S. M., Wiskirchen, R. R., Hagen, K. K., \& Cole, M. L. (2017). Evaluating the temporal location of feedback: Providing feedback following performance vs. prior to performance. Journal of Organizational Behavior Management, 37, 171-195.

Amade-Escot, C. (2016). How gender order is enacted in physical education: The French didactique research approach. In G. Doll-Tepper, K. Koenen, \& R. Bailey (Eds.), Sport, education and social policy (pp. 82-99). Abingdon, United Kingdom: Routledge.

Askew, S., \& Carnell, E. (1998). Transforming learning: Individual and global change. London, United Kingdom: A\&C Black.

Askew, S. (Ed.). (2004). Feedback for learning. London, United Kingdom: RoutledgeFalmer.

BenitezSantiago, A., \& Miltenberger, R. G. (2016). Using video feedback to improve martial arts performance. Behavioral Interventions, 31, 12-27.

Carless, D. (2013). Trust and its role in facilitating dialogic feedback. In D. Boud \& E. Molloy (Eds.), Feedback in higher and professional education: Understanding it and doing it well (pp. 90-103). Abingdon, United Kingdom: Routledge.

Carr, G. (1999). Fundamentals of track and field (2nd ed.). Champaign, IL: Human Kinetics.

Carr, S. E., Brand, G., Wei, L., Wright, H., Nicol, P., Metcalfe, H., ... Foley, L. (2016). "Helping someone with a skill sharpens it in your own mind": A mixed method study exploring health professions students experiences of Peer Assisted Learning (PAL). BMC Medical Education, 16, 48.

Carr, W. D., Volberding, J., \& Vardiman, P. (2011). A peerassisted learning program and its effect on student skill demonstration. Athletic Training Education Journal, 6, 129-135.

Casey, A., \& Jones, B. (2011). Using digital technology to enhance student engagement in physical education. AsiaPacific Journal of Health, Sport and Physical Education, 2, 51-66.

Crook, A., Mauchline, A., Maw, S., Lawson, C., Drinkwater, R., Lundqvist, K., ... Park, J. (2012). The use of video technology for providing feedback to students: Can it enhance the feedback experience for staff and students? Computers \& Education, 58, 386-396.

Crosswhite, J. J., Wilde, K., \& Vescio, J. A. (2003). The relevance of sporting role models in the lives of adolescent girls. ACHPER Australia Healthy Lifestyles Journal, 50(3-4), 31-34.

Daniels, H. (2016). Vygotsky and pedagogy. London, United Kingdom: Routledge.

Dawson, P., van der Meer, J., Skalicky, J., \& Cowley, K. (2014). On the effectiveness of supplemental instruction: A systematic review of supplemental instruction and peerassisted study sessions literature between 2001 and 2010 . Review of Educational Research, 84, 609-639.

Gielen, S., Peeters, E., Dochy, F., Onghena, P., \& Struyven, K. (2010). Improving the effectiveness of peer feedback for learning. Learning and Instruction, 20, 304-315.

Gielen, S., Tops, L., Dochy, F., Onghena, P., \& Smeets, S. (2010). A comparative study of peer and teacher feedback and of various peer feedback forms in a secondary school writing curriculum. British Educational Research Journal, $36,143-162$.

Goodyear, V. A., Casey, A., \& Kirk, D. (2014). Hiding behind the camera: Social learning within the cooperative learning model to engage girls in physical education. Sport, Education and Society, 19, 712-734.

Grycowski, A. J. (2019). An investigation of the effects of peer feedback on cognitive understanding during game play situations in a 7th grade volleyball unit (Master's thesis). University of Wisconsin-Whitewater, Whitewater, WI.

Guay, F., Vallerand, R. J., \& Blanchard, C. (2000). On the assessment of situational intrinsic and extrinsic motivation: The Situational Motivation Scale (SIMS). Motivation and Emotion, 24, 175-213.

Guthrie, M. (2003). Coaching track \& field successfully. Champaign, IL: Human Kinetics.

Hanrahan, S. J., \& Isaacs, G. (2001). Assessing self- and peer-assessment: The students' views. Higher Education Research \& Development, 20, 53-70.

Hardy, C. J., \& Rejeski, W. J. (1989). Not what, but how one feels: The measurement of affect during exercise. Journal of Sport and Exercise Psychology, 11, 304-317.

Hermassi, S., Sellami, M., Bouhafs, E. G., Schwesig, R., \& De Giorgio, A. (2019). Effect of verbal instruction on motor learning ability of anaerobic and explosive exercises in physical education university students. Frontiers in Psychology, 10, 2097.

Hortigüela Alcalá, D., Palacios Picos, A., \& López Pastor, V. (2019). The impact of formative and shared or coassessment on the acquisition of transversal competences in higher education. Assessment \& Evaluation in Higher Education, 44, 933-945.

Hsia, L.-H., Huang, I., \& Hwang, G.-J. (2016). Effects of different online peer-feedback approaches on students' performance skills, motivation and self-efficacy in a dance course. Computers \& Education, 96, 55-71.

Huisman, B., Saab, N., van den Broek, P., \& van Driel, J. (2019). The impact of formative peer feedback on higher education students' academic writing: A meta-analysis. Assessment \& Evaluation in Higher Education, 44, 863-880.

Hung, S.-T. A. (2016). Enhancing feedback provision through multimodal video technology. Computers \& Education, 98, 90-101.

Hunukumbure, A. D., Smith, S. F., \& Das, S. (2017). Holistic feedback approach with video and peer discussion under teacher supervision. BMC Medical Education, 17, 179.

Kim, S., \& Arbel, Y. (2019). Immediate and delayed auditory feedback in declarative learning: An examination of the feedback related event related potentials. Neuropsychologia, 129, 255-262.

Kretschmann, R. (2017). Employing tablet technology for video feedback in physical education swimming class. Journal of E-Learning and Knowledge Society, 13, 103-115.

Lafont, L. (2012). Cooperative learning and tutoring in sports and physical activities. In B. Dyson \& A. Casey (Eds.), Cooperative learning in physical education: A research based approach (pp. 136-149). Abingdon, United Kingdom: Routledge. 
Luck, S. J., \& Vogel, E. K. (1997). The capacity of visual working memory for features and conjunctions. Nature, 390, 279-281.

Maxwell, J., Masters, R., \& Eves, F. (2003). The role of working memory in motor learning and performance. Consciousness and Cognition, 12, 376-402.

Merian, T., \& Baumberger, B. (2007). Le feedback vidéo en éducation physique scolaire [Video feedback in school physical education]. Staps, 76, 107-120.

Mikaelsson, K., Rutberg, S., Lindqvist, A.-K., \& Michaelson, P. (2020). Physically inactive adolescents' experiences of engaging in physical activity. European Journal of Physiotherapy, 22, 191-196.

Owen, M. B., Curry, W. B., Kerner, C., Newson, L., \& Fairclough, S. J. (2017). The effectiveness of school-based physical activity interventions for adolescent girls: A systematic review and meta-analysis. Preventive Medicine, 105, 237-249.

Palao, J. M., Hastie, P. A., Cruz, P. G., \& Ortega, E. (2015). The impact of video technology on student performance in physical education. Technology, Pedagogy and Education, 24, 51-63.

Pearson, N., Braithwaite, R., \& Biddle, S. J. (2015). The effectiveness of interventions to increase physical activity among adolescent girls: A meta-analysis. Academic Pediatrics, 15, 9-18.

Perrenoud, P. (2012). L'organisation du travail, clé de toute pédagogie différenciée [Work organisation, key to every differentiated pedagogy]. Paris, France: ESF.

Potdevin, F., Vors, O., Huchez, A., Lamour, M., Davids, K., \& Schnitzler, C. (2018). How can video feedback be used in physical education to support novice learning in gymnastics? Effects on motor learning, self-assessment and motivation. Physical Education and Sport Pedagogy, 23, 559-574.

Van Gennip, N. A., Segers, M. S., \& Tillema, H. H. (2010). Peer assessment as a collaborative learning activity: The role of interpersonal variables and conceptions. Learning and Instruction, 20, 280-290.

Vaughn, C. J., Kim, E., O’Sullivan, P., Huang, E., Lin, M. Y., Wyles, S., ... Chern, H. (2016). Peer video review and feedback improve performance in basic surgical skills. American Journal of Surgery, 211, 355-360.

Vazou, S., Ntoumanis, N., \& Duda, J. L. (2005). Peer motivational climate in youth sport: A qualitative inquiry. Psychology of Sport and Exercise, 6, 497-516.

Ward, P., \& Lee, M.-A. (2005). Peer-assisted learning in physical education: A review of theory and research. Journal of Teaching in Physical Education, 24, 205-225. 